\title{
Commentary On "Extended Hildebrand Approach: An Empirical Model for Solubility Prediction of Etodolac in 1,4-Dioxane and Water Mixtures"
}

\author{
William E. Acree Jr. ${ }^{1}$
}

Received: 24 July 2017/Accepted: 31 October 2017/Published online: 6 November 2017

(C) Springer Science+Business Media, LLC 2017

\begin{abstract}
Several mathematical errors in the published paper by Rathi and Deshpande ( $\mathrm{J}$ Solution Chem 43:1886-1903, 2014) are identified. The errors concern the incorrect conversion of mass fraction to volume fraction concentrations of 1,4-dioxane, the incorrect conversion of mole fraction solubilities to molar solubilities of Etodolac, and the incorrect calculation of the ideal mole fraction solubility of Etodolac.
\end{abstract}

Keywords Etodolac solubilities · Binary solvent mixtures · Aqueous-dioxane solvent mixtures $\cdot$ Extended hildebrand approach

In a paper published in this Journal Rathi and Deshpande [1] reported the experimental solubilities of binary Etodolac in binary aqueous-1,4-dioxane mixtures at $298.15 \mathrm{~K}$. The authors expressed the experimental data at nine binary solvent compositions and in the two mono-solvents in terms of both mole fraction and molar solubilities. The authors used the extended Hildebrand approach to interpret their measured experimental data.

The purpose of the present communication is to point out several errors in the published paper. The errors involve both the actual experimental values, as well as the authors' interpretation, which contains several miscalculated values. Readers need to be aware of these errors. First, in Table 1 of the published paper [1] the authors give the compositions of the nine binary solvent mixtures in terms of mass fraction and volume fraction $\left(\phi_{\text {dioxane }}\right)$ of 1,4-dioxane. The numerical values that are tabulated in Table 1 for the two concentration units are not consistent with each other. This can easily be shown by converting the tabulated mass fraction compositions of 1,4-dioxane to $\phi_{\text {dioxane }}$ using the authors'

William E. Acree Jr.

acree@unt.edu

1 Department of Chemistry, University of North Texas, 1155 Union Circle Drive \#305070, Denton, TX 76203, USA 
Table 1 Calculated excess molar volumes, $V^{\mathrm{ex}}$, of binary aqueous-1,4-dioxane mixtures using the measured densities, $\rho_{\text {mixture }}$. Reproduced with permission from Rathi and Deshpande [1]

\begin{tabular}{lllll}
\hline$M_{\text {dioxane }}$ & $X_{\text {dioxane }}$ & $X_{\text {water }}$ & $\rho_{\text {mixture }}\left(\mathrm{g} \cdot \mathrm{cm}^{-3}\right)$ & $V^{\text {ex }}\left(\mathrm{cm}^{3} \cdot \mathrm{mol}^{-1}\right)$ \\
\hline 0.0000 & 0.0000 & 1.0000 & 0.9998 & 0 \\
0.1000 & 0.0222 & 0.9778 & 1.0032 & -0.0016 \\
0.2000 & 0.0486 & 0.9514 & 1.0066 & -0.0030 \\
0.3000 & 0.0806 & 0.9194 & 1.0101 & -0.0065 \\
0.4000 & 0.1200 & 0.8800 & 1.0135 & -0.0076 \\
0.5000 & 0.1698 & 0.8302 & 1.0169 & -0.0083 \\
0.6000 & 0.2347 & 0.7653 & 1.0203 & -0.0085 \\
0.7000 & 0.3230 & 0.6770 & 1.0237 & -0.0079 \\
0.8000 & 0.4499 & 0.5501 & 1.0272 & -0.0106 \\
0.9000 & 0.6479 & 0.3521 & 1.0306 & -0.0075 \\
1.0000 & 1.0000 & 0.0000 & 1.034 & 0 \\
\hline
\end{tabular}

measured densities of the binary solvents $\left(\rho_{1}\right)$ that are given in column 4 of Table 1 . The authors did not specify whether the volume fraction concentrations of 1,4-dioxane pertained to the ideal volume fraction of the "solute free" binary solvent mixture or the "solute free" actual volumes of the binary solvent mixture, so I have calculated both numerical values as given below:

$$
\begin{aligned}
\varphi_{\text {dioxane }}^{\text {ideal }} & =\frac{\text { Mass fraction dioxane } / \text { Density of dioxane }}{(\text { Mass fraction of dioxane/Density of dioxane })+(\text { Mass fraction of water/Density of water })} \\
& =\frac{0.1 / 1.0340}{(0.1 / 1.0340)+(0.9 / 0.9998)}=0.0970
\end{aligned}
$$

$$
\begin{array}{r}
\varphi_{\text {dioxane }}^{\text {actual }} \approx \frac{\text { Mass fraction of dioxane/Density of dioxane }}{1 / \text { Density of binary solvent mixture }} \\
\approx \frac{0.1 / 1.0340}{1 / 1.0056}=0.0973
\end{array}
$$

Equation 1 assumes that the volumes of the two solvent components are additive, whereas Eq. 2 uses the measured density to calculate the volume of the binary solvent mixture. Neither calculated value is close to the volume of fraction of $\varphi_{\text {dioxane }}=0.1105$ that the authors give in the second column of Table 1 for a 1,4-dioxane mass fraction of 0.1000 . Published applications using the Hildebrand and extended Hildebrand approach normally use ideal volume fraction compositions for the initial solvent concentration.

In Table 1 of the published paper [1] the authors report the solubility of Etodolac in terms of both mole fraction and molar $\left(\mathrm{mol} \cdot \mathrm{L}^{-1}\right)$ solubilities. The two sets of experimental values are inconsistent with each other. The molar solubilities of Etodolac that are given in column 7 of Table 1 should be much larger than the mole fraction solubilities that are given in column 8 . Mole fraction solubilities are converted to molar solubilities by dividing by the molar volume of the saturated solution given in $\mathrm{L} \cdot \mathrm{mol}^{-1}$. What I suspect that the authors have done is to divide by the volume in $\mathrm{cm}^{3} \cdot \mathrm{mol}^{-1}$ as this is the only logical explanation that I have for why the molar solubilities are so very much smaller than the mole fraction solubilities. 
Also in the paper [1] the authors calculate the ideal mole fraction solubility of Etodolac, $X_{\text {solute }}^{\text {ideal }}$, at $298.15 \mathrm{~K}$ based on:

$$
\log _{10} X_{\text {solute }}^{\text {ideal }}=-\frac{\Delta H_{\text {fus }}\left(T_{\text {fus }}-298.15\right)}{2.303 \times 298.15 R T_{\text {fus }}}
$$

where $R$ is the universal gas constant, $T_{\text {fus }}$ is the melting point temperature of Etodolac (given in the paper as $426.89 \mathrm{~K}$ ), and $\Delta H_{\text {fus }}$ is the molar enthalpy of fusion of Etodolac (given as $91.09 \mathrm{~J} \cdot \mathrm{g}^{-1} \times 287.35 \mathrm{~g} \cdot \mathrm{mol}^{-1}=26175 \mathrm{~J} \cdot \mathrm{mol}^{-1}$ ). Substituting numerical values of $\Delta H_{\text {fus }}=26175 \mathrm{~J} \cdot \mathrm{mol}^{-1}$ and $T_{\text {fus }}=426.89 \mathrm{~K}$ into Eq. 3, I calculate a value of $X_{\text {solute }}^{\text {ideal }}=0.04142$, which differs considerably from the value of $X_{\text {solute }}^{\text {ideal }}=0.0071$ that the authors calculated. Clearly there is a problem with either the authors' calculated value of $X_{\text {solute }}^{\text {ideal }}$ or their measured melting point temperature and/or enthalpy of fusion. The authors' calculated value of $X_{\text {solute }}^{\text {ideal }}$ is not consistent with the enthalpy of fusion and melting point data reported in their published paper.

I note that the authors did use their calculated value of $X_{\text {solute }}^{\text {ideal }}=0.0071$ to compute the activity coefficient of Etodolac in the saturated solutions, e.g., $\gamma_{\text {solute }}^{\text {obs }}=X_{\text {solute }}^{\text {ideal }} / X_{\text {solute }}^{\text {exp }}$. The authors' expressed the calculated activity coefficients as $\log _{10} \gamma_{\text {solute }}^{\text {obs }}$. Using the authors' value of $X_{\text {solute }}^{\text {ideal }}=0.0071$ for the ideal mole fraction solubility of Etodolac and $X_{\text {solute }}^{\exp }=0.0001126$ for the mole fraction solubility of Etodolac in water, I obtain a value of $\log _{10} \gamma_{\text {solute }}^{\text {obs }}=1.7997$, which differs from the value $\log _{10} \gamma_{\text {solute }}^{\text {obs }}=2.7978$ that the authors report in the last column of Table 1 [1]. Clearly there is a problem with the authors' tabulated numerical value. The rest of the numerical values in the last column of Table 1 are similarly off by one $\log _{10}$ unit as well, assuming that $X_{\text {solute }}^{\text {ideal }}=0.0071$ was correct.

It is possible to evaluate the "quality" of the authors' experimental density data for each of the nine binary solvent compositions at which the density was measured. There is both published experimental density and excess molar volume data in the published literature. Both Ouerfelli et al. [2] and Aminabhavi and Gopalakrishna [4] measured densities of binary aqueous-1,4-dioxane mixtures at $298.15 \mathrm{~K}$ over the entire concentration range. It is difficult to compare the densities directly, as each research group performed measurements at different mixture concentrations. What I have done is to convert the 1,4-dioxane mass fractions given in the first column of Table 1 [1] to mole fractions, $X_{\text {dioxane }}$ and $X_{\text {water }}$, and then used these values to calculate the excess volumes, $V^{\mathrm{ex}}$, for each solvent composition according to Eq. 4 below:

$$
V^{\text {ex }}=\frac{X_{\text {dioxane }} M W_{\text {dioxane }}+X_{\text {water }} M W_{\text {water }}}{\rho_{\text {mixture }}}-\frac{X_{\text {dioxane }} M W_{\text {dioxane }}}{\rho_{\text {dioxane }}}-\frac{X_{\text {water }} M W_{\text {water }}}{\rho_{\text {water }}}
$$

where $M W_{i}$ and $\rho_{i}$ refer to the molar mass and density of the respective solvent component $i$. Tabulated in Table 1 of this commentary are the results of my calculations. The excess molar volumes that I calculate are extremely small and would indicate the water and 1,4dioxane form a nearly ideal binary solvent mixture, as far as excess molar volumes is concerned. Ouerfelli and coworkers [2], Iulian and Ciocirlan [3], Aminabhavi and Gopalakrisha [4], and Morcom and Smith [5] report excess molar volumes of $V^{\text {ex }}=-0.626 \mathrm{~cm}^{3} \cdot \mathrm{mol}^{-1}, \quad V^{\mathrm{ex}}=-0.629 \mathrm{~cm}^{3} \cdot \mathrm{mol}^{-1}, \quad V^{\mathrm{ex}}=-0.624 \mathrm{~cm}^{3} \cdot \mathrm{mol}^{-1}$ and $V^{\mathrm{ex}}=-0.601 \mathrm{~cm}^{3} \cdot \mathrm{mol}^{-1}$, respectively, at $X_{\text {dioxane }}=0.50$. The experimental densities reported by Rathi and Deshpande [1] do not appear to be of sufficient "quality" for excess molar volume calculations. 
As an informational note, readers should be very cautious of explanations and equations based on or derived from incorrectly calculated values of $\phi_{\text {dioxane }}$ and $X_{\text {solute }}^{\text {ideal }}$. I also suspect that the numerical values of the solubility parameters in the third column of Table 1 are also miscalculated. Normally the solubility parameter of the solvent, $\delta_{\text {binary mixture, is }}$ calculated as $[6,7]$ :

$$
\delta_{\text {binary mixtrue }}=\phi_{\text {solvent } 1} \delta_{\text {solvent } 1}+\phi_{\text {solvent } 2} \delta_{\text {solvent } 2}
$$

an initial volume fraction average of the solubility parameters of the two mono-solvents ( $\delta_{\text {solvent } 1}$ and $\delta_{\text {solvent } 2}$ ) that make up the binary solvent mixture. I cannot reproduce the solubility parameters of the binary solvent mixture that the authors give in Table 1 of their published paper [1].

\section{References}

1. Rathi, P.B., Deshpande, K.V.: Extended Hildebrand approach: an empirical model for solubility prediction of Etodolac in 1,4-dioxane and water mixtures. J. Solution Chem. 43, 1886-1903 (2014)

2. Ouerfelli, N., Barhoumi, Z., Besbes, R., Amdouni, N.: The reduced Redlich-Kister excess molar Gibbs energy of activation of viscous flow and derived properties in 1,4-dioxane + water binary mixtures from 293.15 to 309.15 K. Phys. Chem. Liq. 49, 777-800 (2011)

3. Iulian, O., Ciocirlan, O.: Viscosity and density of systems with water, 1,4-dioxane and ethylene glycol between (293.15 and 313.15) K. I. Binary systems. Rev. Roumaine Chim. 55, 45-53 (2010)

4. Aminabhavi, T.M., Gopalakrishna, B.: Density, viscosity, refractive index, and speed of sound in aqueous mixtures of $N, N$-dimethylformamide, dimethyl sulfoxide, $N, N$-dimethylacetamide, acetonitrile, ethylene glycol, diethylene glycol, 1,4-dioxane, tetrahydrofuran, 2-methoxyethanol, and 2-ethoxyethanol at 298.15 K. J. Chem. Eng. Data 40, 856-861 (1995)

5. Morcom, K.W., Smith, R.W.: Thermodynamic behavior of aqueous solutions of cyclic ethers. I. Enthalpies and volumes of mixing. Trans. Faraday Soc. 66, 1073-1080 (1970)

6. Gordon, L.J., Scott, R.L.: Enhanced solubility in solvent mixtures. I. The system phenanthrene-cyclohexane-methylene iodide. J. Am. Chem. Soc. 74, 4138-4140 (1952)

7. Jouyban-Gharamaleki, A., Romero, S., Bustamante, P., Clark, B.J.: Multiple solubility maxima of oxolinic acid in mixed solvents and a new extension of Hildebrand solubility approach. Chem. Pharm. Bull. 48, 175-178 (2000) 